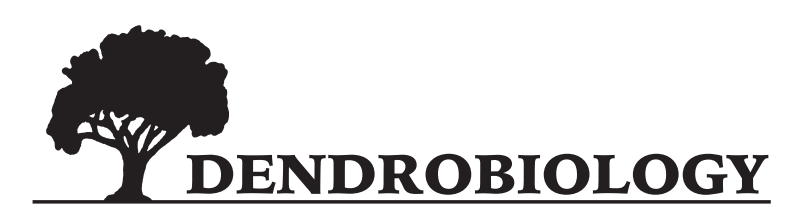

2020, vol. 83, 30-42

http://dx.doi.org/10.12657/denbio.083.003

\author{
Dominika Thiem, Jarostaw Tyburski, Marcin Gotębiewski, \\ Katarzyna Hrynkiewicz*
}

\title{
Halotolerant fungi stimulate growth and mitigate salt stress in Alnus glutinosa Gaertn.
}

Received: 5 April 2020; Accepted: 25 May 2020

\begin{abstract}
Soil salinity is an important abiotic stress factor that reduces both plant growth and development and decreases diversity and metabolic potential of microorganisms, particularly fungi. However, some fungal isolates, including mycorrhizal fungi, can increase tolerance of plants to salinity, e.g. by activation of defense mechanisms. Main aim of our study was: (i) to identify and characterize fungal strains isolated from fruitbodies growing at saline test sites and (ii) to determine the effect of fungal inoculation on the growth and salinity tolerance of Alnus glutinosa Gaertn. seedlings. Two ectomycorrhizal strains (Amanita muscaria OW-10 and Paxillus involutus OW-5) and a saprotrophic one (Gymnopus sp. OW-6) were isolated from fruitbodies collected at naturally saline test sites. The plant growth promotion was observed after inoculation of plants with the ectomycorrhizal fungus - P. involutus OW-5, while the use of Gymnopus sp. OW-6, displaying the highest hydrolytic activity, decreased seedling growth parameters. Moreover, $P$. involutus OW-5 (characterized by characterized by medium salt tolerance salt tolerance) promoted growth of black alder in the presence of salt, while A. muscaria OW-10 (with the highest salt tolerance) increased fresh and dry mass of seedlings only in the absence of salt. Black alder seedlings inoculated with $P$. involutus OW-5 revealed higher synthesis of proline in aboveground organs compared to the control plants which suggested that accumulation of this compound can be a mechanism protecting black alder seedlings against salt stress. In conclusion, we recommend the use of $P$. involutus OW-5, which displayed the best plant growth promoting ability and salt tolerance, for inoculation of black alder trees used in reclamation of saline habitats.
\end{abstract}

Keywords: black alder, ectomycorrhiza, saprophytic fungi, inoculation, proline

Addresses: D. Thiem, K. Hrynkiewicz, Department of Microbiology, Faculty of Biological and Veterinary Sciences, Nicolaus Copernicus University, Lwowska 1, 87-100 Torun, Poland, e-mail: hrynk@umk.pl D. Thiem, J. Tyburski, M. Gołębiewski, K. Hrynkiewicz, Centre of Modern Interdisciplinary Technologies, NCU, Wileńska 4, 87-100 Torun, Poland

J. Tyburski, M. Gołębiewski, Chair of Plant Physiology and Biotechnology, Faculty of Biological and Veterinary Sciences, NCU, Lwowska 1, 87-100 Torun, Poland

${ }^{*}$ Corresponding author

\section{Introduction}

The process of soil salinization is a widespread problem at the global scale and can significantly limit growth of plants inhabiting temperate and boreal forests (Aguilar-Aguilar et al., 2009). Furthermore, elevated salt levels decrease density, diversity and activity of microorganisms associated with forest trees (Yan et al., 2015; Thiem et al., 2018). To date, most research was focused on improvement of salt 
tolerance in non-woody, herbaceous plants (e.g.; Sharma et al., 2016; Szymańska et al., 2019). However, salinity is more problematic for trees, since they have to withstand unfavorable environmental conditions for longer time (Chen et al., 2014). For this reason more effort should be put into finding ways of improving salt tolerance in trees. Application of mycorrhizal fungi could be a good solution.

Alnus glutinosa Gaertn. (black alder) forms tripartite symbiotic interaction with ectomycorrhizal (EM) and arbuscular mycorrhizal fungi as well as bacteria belonging to the Frankia genus. This tree species can grow in soils affected by diverse environmental stresses, e.g. drought, flooding (Diagne et al., 2013), high $\mathrm{pH}$ as well as salinity (Beaudoin-Nadeau et al., 2016). Due to this fact, alders have been planted in different European regions for erosion control and to improve soil fertility (Oliveira et al., 2014). In our previous studies we have observed that black alder can naturally grow in regions where salinity does not exceed $5 \mathrm{dS} \mathrm{m}^{-1}$ (Thiem et al., 2018). Moreover, microbiome of black alder growing in saline soil consists of many symbionts, potentially important for tree survival (Thiem et al., 2018).

Fungal inoculation has been frequently recommended for improvement of trees salinity tolerance (Li et al., 2012; Chen et al., 2014). There are several studies on the role of arbuscular mycorrhiza in modulating salt response in herbaceous plants (Giri \& Mukerji, 2004; Tain et al., 2004), whereas only few studies were focused on the role of EM fungi in protection of trees against salinity (e.g.; Bandou et al., 2006; Langenfeld-Heyser et al., 2007). EM fungi display genetic potential to produce many extracellular substances which may be helpful in alleviating stress in host plant, e.g. due to salinity. The association with EM fungi allows trees to explore large volume of soil to absorb more water and nutrients (Beltrano et al., 2013; Séne et al., 2015). Moreover, EM fungi can increase tolerance of host-plants to salinity by ion-homeostasis regulation, protection of enzyme activities and activation of defense response (Beltrano et al., 2013; Chen et al., 2014). EM fungi can also activate specific genes responsible for (1) synthesis of osmolytes such as proline, sugars and polyols; (2) encoding antioxidant enzymes that decrease amount of reactive oxygen species or (3) synthesis of enzymes participating in glutathione synthesis (Langenfeld-Heyser et al., 2007). Under salt stress conditions the role of proline consists in scavenging hydroxyl radicals and protecting of cytosolic enzymes and cellular organelles, thus maintaining normal osmotic conditions (Hajiboland et al., 2010; Zarei \& Paymaneh, 2014). Most studies have showed accumulation of this compound in tissues of mycorrhizal plants which resulted in protection of inoculated plants (Sharifi et al., 2007; Zou \& Wu, 2011).
Vital ectomycorrhizal symbiosis can improve growth of trees and reduce damage caused by plant pathogens. This aspect is particularly important in case of Alnus, since many fungal diseases led to high mortality of this species across Western, Central and Northern Europe over the past several years (Solla et al., 2010; Markovskaja, 2013).

Apart from the EM fungi, saprobes largely contribute to microbial biomass in forest ecosystems (Högberg \& Högberg, 2002; Dutta et al., 2015). The saprophytic fungi are responsible for decaying organic matter and play an important role in the cycling of carbon, nitrogen, and other soil nutrients (Smith \& Read, 2008). The spectrum of decomposed compounds of each fungal species varies depending on environmental conditions (Kubartová et al., 2009). For this reason, the presence of saprophytic fungi in the proximity of tree roots can influence the tree growth indirectly by nutrients releasing. The role of saprophytic fungi in plant growth promotion under abiotic stress conditions, such as salinity, is still unclear.

It should be stressed that practical application of EM or saprophytic fungal species is limited by their lack of salinity tolerance. Until now, in vitro studies on salt tolerance of basidiomycetes fungi have shown that they are generally salt sensitive (Chen et al., 2001; Kernaghan et al., 2002). Salt tolerance of EM fungi has been observed only in case of a few species, e.g. Laccaria bicolor, Hebeloma crustuliniforme or Pisolithus sp. (Kernaghan et al., 2002; Chen et al., 2001).

However, many previous studies have shown that salt affected environments are rich in halotolerant fungi (Cantrell et al., 2006; Evans et al., 2013; Furtado et al., 2019). For this reason, the specific aims of our study were: (i) to collect fruitbodies growing under A. glutinosa trees at saline test sites, identify fungal isolates and analyze their plant growth promoting properties; (ii) to select strains promoting growth and increasing salinity tolerance of A. glutino$s a$ seedlings for application in saline habitats reclamation. We hypothesize that $(\mathrm{H} 1)$ fungal strains isolated from fruitbodies at saline test sites will show a high salt tolerance and plant growth promoting properties. Moreover, we suppose that (H2) inoculation of seedlings with selected fungal strains will alleviate salt stress in plants by increasing the levels of proline.

\section{Methods}

\section{Site description, sampling and fungal material}

The study was carried out in Słonawy $\left(53^{\circ} 01^{\prime} 26.66^{\prime \prime} \mathrm{N}, 17^{\circ} 37^{\prime} 47.3^{\prime \prime} \mathrm{E}\right)$ localized in northern part of Poland where weather conditions are typical for moderate climate. The main cause of salinity 
were saline springs contacting with the Zechstein (Permian) salt deposits (Dadlez \& Jaroszewski, 1994). Analyzed area is a monoculture of A. glutinosa Geartn. trees. The groundcover is almost exclusively dominated by nettle (Urtica dioica). Fruitbodies were sampled in September 2015 under the nineteenyears-old black alder and transported immediately to the laboratory in plastic containers with small holes. Then fruitbodies were cleaned under sterile conditions and cut in half using sterile scalpel. Five pieces $(5 \times 5 \mathrm{~mm})$ were cut from the interior part of each fruitbody and placed on the PDA medium (Becton Dickinson, USA) containing ampicillin (50 mg/l) (Sigma-Aldrich, Poland). Plates were incubated at $25^{\circ} \mathrm{C}$ for one month in darkness to obtain sterile fungal mycelium. Finally, fungal mycelium was obtained from seven fruitbodies.

\section{Molecular and phylogenetic analysis}

DNA from isolated fungal strains was extracted from mycelium using the Plant \& Fungi Purification Kit (EurX, Poland) according to the manufacturer's protocol. The fungal taxa were identified based on the internal transcribed spacer (ITS) region of the rDNA according to the methodology described by Hrynkiewicz et al. (2015). The National Center for Biotechnology Information (NCBI) GenBank database and UNITE (Nilsson et al., 2018) were used for sequence comparisons. We required $99 \%$ identity for strain identification. ITS fungal sequences were assembled into contigs and aligned with the closest BLAST matches of published sequences (GenBank/ UNITE) using Clustal W (Thompson et al., 1997). Phylogenetic relationships was inferred using the Neighbor-Joining method (Saitou \& Nei, 1987) using Mega X, version 5 (Kumar et al., 2018). The evolutionary distances were computed using the Maximum Composite Likelihood method (Tamura et al., 2004) and support for branching was obtained from bootstrap analysis performed using 1000 replicates (Felsenstein, 1985).

\section{Evaluation of the plant growth promotion properties of fungal strains}

To analyze hydrolytic potential, fungal strains were cultivated for 14 days on media containing different substrates: tributyrin (Sigma-Aldrich, $>97 \%$ ) to test for lipases and esterases, starch $(\mathrm{POCH}$, $\geq 99 \%$ ) to test for amylases (Gibson \& Gordon, 1974), casein (Sigma-Aldrich, $\geq 98 \%$ ) to test for proteases (Burbianka \& Pliszka, 1977), carboxymethylcellulose (Sigma-Aldrich) to test for cellulases (Berg \& Pettersson, 1977), $\mathrm{K}_{2} \mathrm{HPO}_{4}, \mathrm{Ca}_{3}\left(\mathrm{PO}_{4}\right)_{2}$ (Chempur, Poland, $\geq 99 \%$ ) to test for phosphatases (Pikovskaya,
1948) and colloid chitin (Sigma-Aldrich) to test for chitinases (Lingappa \& Lockwood, 1962). Additionally, the ability to synthesize secondary metabolites was studied (after 14 days of cultivation): siderophores on CAS medium (Alexander \& Zuberer, 1991) and polyamines on the medium supplemented with L-arginine (Sigma-Aldrich, $\geq 98 \%$ ) (Amprayan et al., 2012). The coefficient of activity $\left(W_{\text {act }}\right)$ was calculated using the following formula, proposed by Hrynkiewicz et al. (2010):

$$
\mathrm{W}_{\mathrm{act}}=\mathrm{S}_{\mathrm{h}}{ }^{2} /\left(\mathrm{S}_{\mathrm{c}} \times \mathrm{t}\right)
$$

where $S_{h}$ is the diameter of the hydrolysis zone, $S_{c}$ is the colony diameter, and $t$ is the incubation time.

Analysis of indole-3-acetic acid (IAA) (Sigma-Aldrich, $\geq 98 \%$ ) (Chang et al., 2014) and ACC (1-aminocyclopropane-1-carboxylate) (Sigma-Aldrich, $298 \%$ ) deaminase production (Amprayan et al., 2012) were performed in liquid MMN medium (50 ml per $100 \mathrm{ml}$ flask) supplemented respectively in $0.1 \mathrm{~g} / \mathrm{L}$ L-tryptophan (Sigma-Aldrich, $\geq 99 \%$ ) and $3.0 \mathrm{mM}$ (filter sterilized) ACC as sole nitrogen source after one month of cultivation $\left(25^{\circ} \mathrm{C}\right.$, $120 \mathrm{rpm}$ ). All metabolic activities were analyzed in triplicate for each fungal strain. Non- inoculated media were incubated at the same conditions and used as negative controls.

\section{Salt tolerance of fungal strains}

Fungal strains were inoculated on PDA (Becton Dickinson) medium containing different concentrations of sodium chloride $(0,50,100,200,300,400$ $\mathrm{mM} \mathrm{NaCl}$ ) in triplicate. After one month of cultivation diameters of fungal colonies were measured.

\section{Effect of fungal inoculation on the growth and salt tolerance of black alder seedlings}

Containers $(0.25 \mathrm{l})$ were surface sterilized with alcohol and filled with 0.21 of sterile vermiculite and sand mixture $(1: 1 \mathrm{v} / \mathrm{v})$. Plants were grown in two variants of substrate: (i) control without $\mathrm{NaCl}(0 \mathrm{mM}$, $-\mathrm{NaCl}$ ) and (ii) saline with $50 \mathrm{mM}$ of $\mathrm{NaCl}$ (Chempur, $\geq 99 \%)(+\mathrm{NaCl})$. Depending on the treatment, plants were watered either with Hoagland's medium without or with $50 \mathrm{mM} \mathrm{NaCl}$. Black alder seeds (source: Forestry Dobrzejewice, Toruń, Poland) were surface sterilized with hydrogen peroxide $(30 \%, 20$ $\min$ ), washed five times with distilled water and sown in containers. Plants were grown in a greenhouse under natural light conditions at $22-24^{\circ} \mathrm{C}$. Inoculation was performed after 8 weeks, when seedlings reached height of $3 \mathrm{~cm}$. For both substrates 
four variants of inoculation were prepared: control (no inoculation), and A. muscaria OW-10, Gymnopus sp. OW-6, as well as P. involutus OW-5 inoculation (8 plants per variant, 64 in total). Mycelia were cultivated in liquid Hagem's medium (McLaughlin, 1970) for four weeks at $25^{\circ} \mathrm{C}$ with shaking (120 rpm). Obtained cultures were centrifuged $(10 \mathrm{~min} ., 3000 \times \mathrm{g})$ and washed three times with sterile $0.9 \% \mathrm{NaCl}(50$ $\mathrm{ml})$. Finally, mycelia were vortexed for $5 \mathrm{~min}$ in sterile $50 \mathrm{ml}$ falcon tubes with $10 \mathrm{ml}$ of glass beads and $20 \mathrm{ml}$ of $0.9 \% \mathrm{NaCl}$. Each inoculum was diluted with $0.9 \% \mathrm{NaCl}$ to bring its $\mathrm{OD}_{565}=1.0$. One hundred microliters of each inoculum was cultivated on PDA medium at $25^{\circ} \mathrm{C}$ in the dark to check the their quality. Inoculum ( $0.5 \mathrm{ml}$ per plant) was provided to the root zone. Once per week plants were watered using Hoagland's medium (50 ml/plant), while distilled water was provided according to demand. Six weeks after inoculation, plants were gently uprooted, washed in distilled water to remove the substrate and measured (stems and roots length). Roots were observed under stereomicroscope to verify the presence of mycorrhizal tips. Fresh mass of leaves, stems and roots was determined and dry mass of the organs was measured after drying at $60^{\circ} \mathrm{C}$ for $24 \mathrm{~h}$. Growth parameters were analyzed for five plants per variant. Remaining plant material (3 plants per variant) was weighted and flash-frozen in liquid nitrogen for analysis of proline level, which was measured for each plant organ in triplicates according to procedure described by Ábrahám et al. (2010). Fifty mg of roots from each variant were frozen at $-20^{\circ} \mathrm{C}$ and used for DNA isolation and PCR reaction checking presence of fungi. PCR reaction conditions were described above (Molecular and phylogenetic analysis).

\section{Statistical analyzes}

All data obtained in in vitro tests and pot experiment were tested by Levene's tests for homogeneity of variance and by Shapiro-Wilk's normality test. Significant differences between $\mathrm{W}_{\text {act }}$ values for synthesis of lipases, amylases, DCP and siderophores were tested separately using one-way ANOVA with Newman-Keuls's test as post hoc analysis. Principal Component Analysis (PCA) was used to visualize all $\mathrm{W}_{\mathrm{act}}$ values obtained for synthesis of hydrolytic enzymes and secondary metabolites by all tested fungal strains. Significance of differences in fungal growth was assessed by one-way ANOVA and NewmanKeuls's post hoc test. Heat map illustrating tolerance to $\mathrm{NaCl}$ was prepared using conditional formatting in Microsoft Exel (2010).The effect of salinity, fungal inoculation, and salinity $\times$ fungal inoculation on the growth parameters (stems and roots length, fresh and dry mass of organs) and the levels of proline in plant organs were tested by two-way ANOVA and Newman-Keuls's tests as post hoc analysis. P-value $\leq$ 0.05 was assumed significant in all conducted tests. Statistical analysis was performed using program Statistica (ver. 8, StatSoft, 2007). Figures were prepared in Microsoft Excel (2010) and Inkscape (ver. 0.92.2).

\section{Results}

\section{Fungal isolates identification and phylogenetic analysis}

Three isolated strains turned out to be identical in terms of ITS sequence and belonged to Amanita

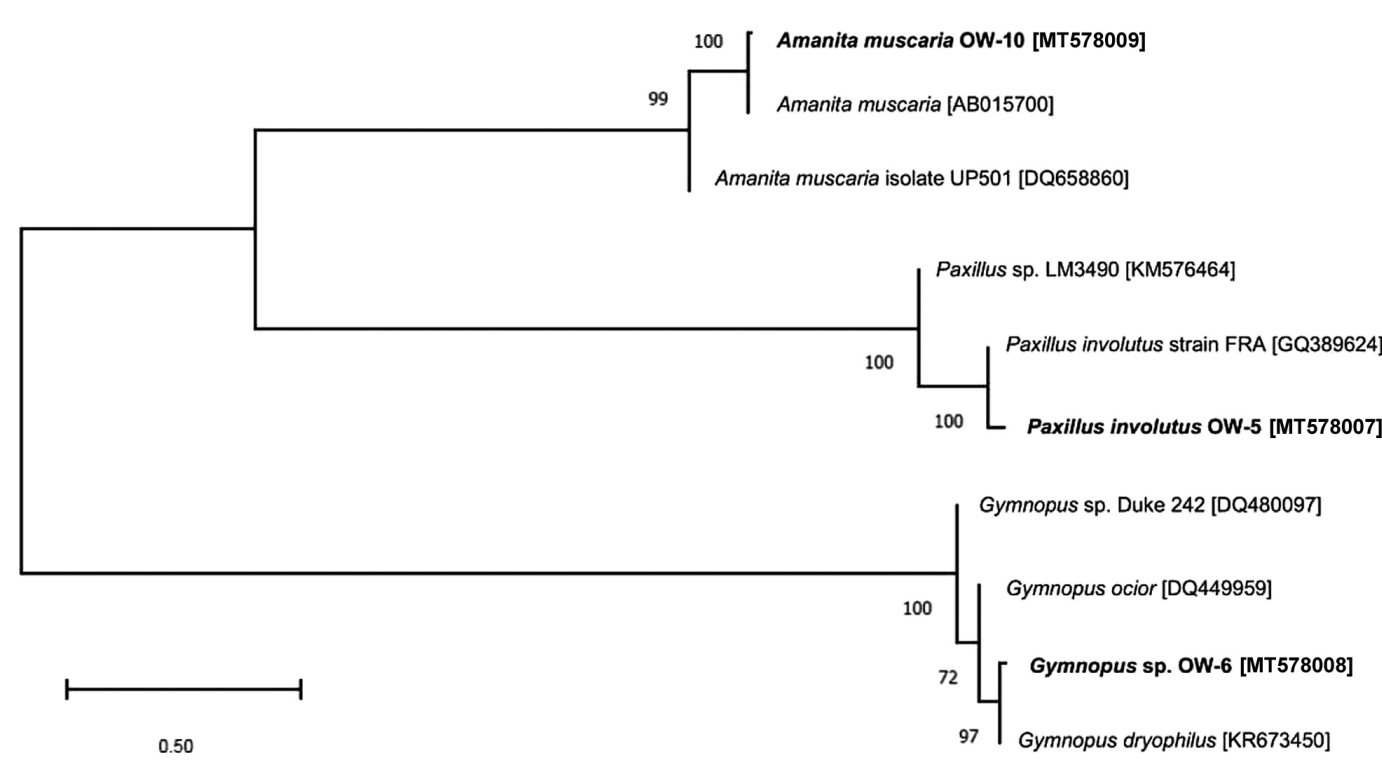

Fig. 1. Phylogenetic relationships of three halotolerant fungal strains. Neighbour-joining analysis of internal transcribed spacer (ITS), using Maximum Likelihood method to calculation genetic distances, combined with bootstrap analysis from 1,000 replicates (bootstrap values $<50 \%$ not shown) 
muscaria - an ectomycrrhizal species of Agaricales. The closest relative of these strains was $A$. muscaria AB015700 (99.5\% identity). Two identical strains belonged to Paxillus involutus of Boletales, also an ectomycorrhizal species. Their closest relative was $P$. involutus FRA GQ389624 (99\% identity). The remaining two strains also were identical and belonged to the Gymnopus genus of uncertain systematic position. In this case, the closest relatives were G. dryophilus (99.5\% identity) and G. ocior (99\% identity), which precluded species-level assignment (Fig. 1). Fungi belonging to this genus are saprophytes but occasionally also attack living wood (Jang et al., 2016). The sequences of fungal strains were deposited in NCBI database: A. muscaria OW-10 [MT578069], Gymnopus sp. OW-6 [MT578068], P. involutus [MT578067]. Based on phylogenetic analysis, one strain of each species was chosen for plant inoculation and physiological characterization.

\section{Hydrolytic activities, plant-growth- promoting properties and tolerance to salinity of isolated fungal strains}

Gymnopus sp. OW-6 showed higher metabolic activity compared to both ectomycorrhizal fungi. This strain synthesized hydrolytic enzymes belonging to five different classes, with the highest level of carboxymethylcellulose and casein hydrolysis (Fig. 2, Table 1). A. muscaria OW-10 and P. involutus OW-5 displayed only two activities each: both were amylolytic, and phosphatese was specific for the former, while lipase for the latter (Fig. 2, Table 1). Of the three strains, $P$. involutus OW-5 was the only one synthesizing polyamines and produced highest level of siderophores (13 times more than A. muscaria OW-10 and $\sim 3$ times more that Gymnopus sp. OW-6 (Table 1). Chitinases and triphosphatases were not synthesized by analyzed fungi. None of the tested fungal strains synthesized IAA nor ACC deaminase (Table 1).

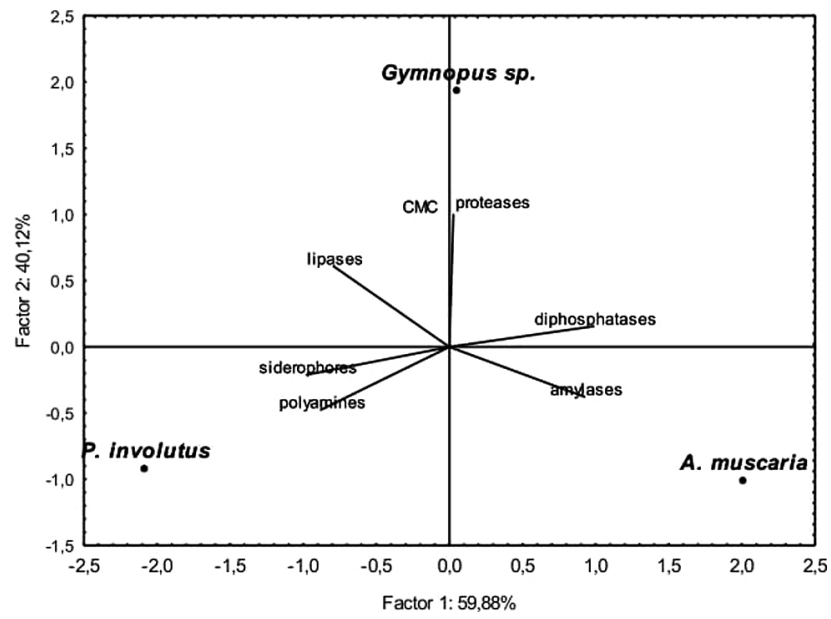

Fig. 2. Fungal activities and properties potentially involved in plant growth promotion

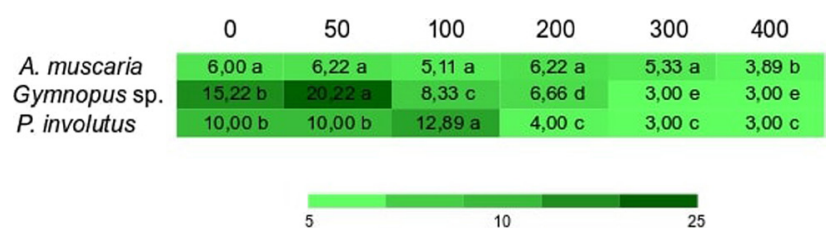

Fig. 3. Heat map of differences in fungal growth and their tolerance to $\mathrm{NaCl}(0-400 \mathrm{mM})$. The intensity of green colour determined average diameter of fungal mycelium.

The highest salt tolerance was observed for $A$. muscaria OW-10, that grew in broad range of salinity and was inhibited only by $400 \mathrm{mM} \mathrm{NaCl}$, albeit the growth was slow, regardless of salt concentration. $P$. involutus OW-5 grew optimally at $100 \mathrm{mM} \mathrm{NaCl}$, but was inhibited by $200 \mathrm{mM}$ salt, while Gymnopus sp. OW-6 grew optimally at $50 \mathrm{mM}$ salt but was significantly inhibited at $100 \mathrm{mM}$ of $\mathrm{NaCl}$ (Fig. 3). Growth of the latter strain was faster, compared to the ectomycorrhizal strains. We observed that pigment production was negatively related to salinity (Supplementary material, Fig. S1).

Table 1 Fungal activities expressed as coefficient of activity $\left(\mathrm{W}_{\mathrm{act}} \pm \mathrm{SD}\right)$ and results of one-way ANOVA for synthesis of lipases, amylases, DCP and siderophores. ${ }^{\text {a }} \mathrm{CMC}$ - carboxymethylcellulases; ${ }^{\mathrm{b}} \mathrm{DCP}$ - diphosphatases; ${ }^{\mathrm{c}} \mathrm{TCP}-\mathrm{triphos}-$ phatases; ${ }^{\mathrm{d}}$ IAA - indole-3-acetic acid; ${ }^{\mathrm{e}}$ ACC - 1-aminocyclopropane-1-carboxylate

\begin{tabular}{|c|c|c|c|c|c|c|}
\hline & & A. muscaria OW-10 & Gymnopus sp. OW-6 & P. involutus OW-5 & $\mathrm{F}$ & $\mathrm{p}$ \\
\hline \multirow[t]{7}{*}{ hydrolytic activity } & lipases & - & $9.94 \pm 0.77 \mathrm{a}$ & $8.80 \pm 0.66 a$ & 3.77 & 0.1242 \\
\hline & amylases & $5.79 \pm 1.05 \mathrm{a}$ & $4.78 \pm 0.59 a$ & $4.57 \pm 0.59 \mathrm{a}$ & 2.45 & 0.1766 \\
\hline & proteases & - & $1.09 \pm 0.10$ & - & - & - \\
\hline & $\mathrm{CMC}^{\mathrm{a}}$ & - & $7.21 \pm 2.38$ & - & - & - \\
\hline & $\mathrm{DCP}{ }^{b}$ & $1.39 \pm 0.14 \mathrm{a}$ & $0.92 \pm 0.09 a$ & - & 24.44 & 0.0078 \\
\hline & $\mathrm{TCP}^{\mathrm{c}}$ & - & - & - & - & - \\
\hline & chitinases & - & - & - & - & - \\
\hline \multirow{4}{*}{$\begin{array}{l}\text { plant growth promoting } \\
\text { properties }\end{array}$} & IAA production ${ }^{d}$ & - & - & - & - & - \\
\hline & ACC deaminase ${ }^{e}$ & - & - & - & - & - \\
\hline & siderophores production & $1.73 \pm 0.27 \mathrm{a}$ & $7.89 \pm 1.88 b$ & $23.10 \pm 1.86 c$ & 154.59 & $0.7^{*} 10^{-5}$ \\
\hline & poliamines synthesis & - & - & $1.45 \pm 0.20$ & - & - \\
\hline
\end{tabular}


Fig. 4. Length of (A) stems and (B) roots of seedlings non-inoculated (control) and inoculated with fungi (Amanita muscaria OW-10, Gymnopus sp. OW-6, Paxillus involutus $\mathrm{OW}-5)$ growing in two variants of substrate without $(-\mathrm{NaCl})$ and with salt $(+\mathrm{NaCl})$ presented as means with standard deviation. Means values with the same letter are not significantly different $(\mathrm{p} \leq 0.05$, two-way ANOVA and Newman-Keuls's test). Arrows show significant increase $(\uparrow)$ or decrease $(\downarrow)$ compare to control within the same substrate variant

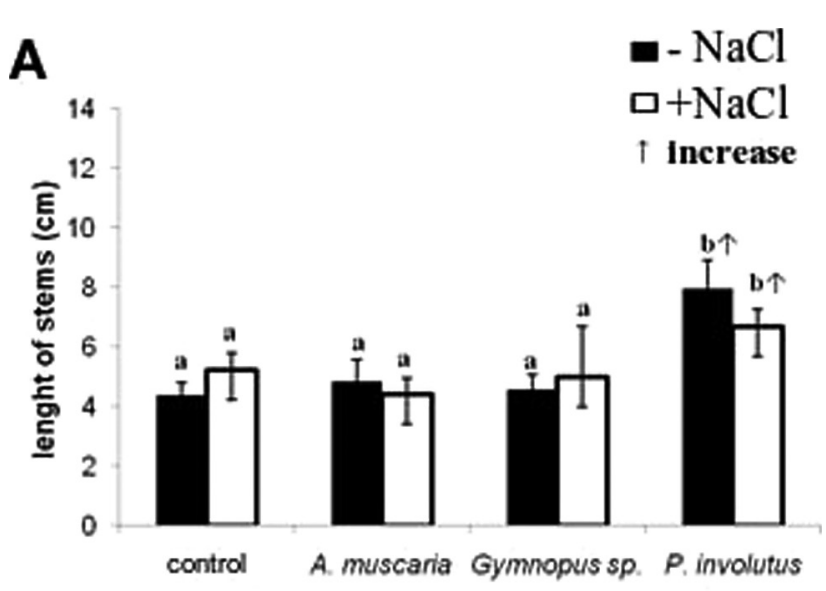

B

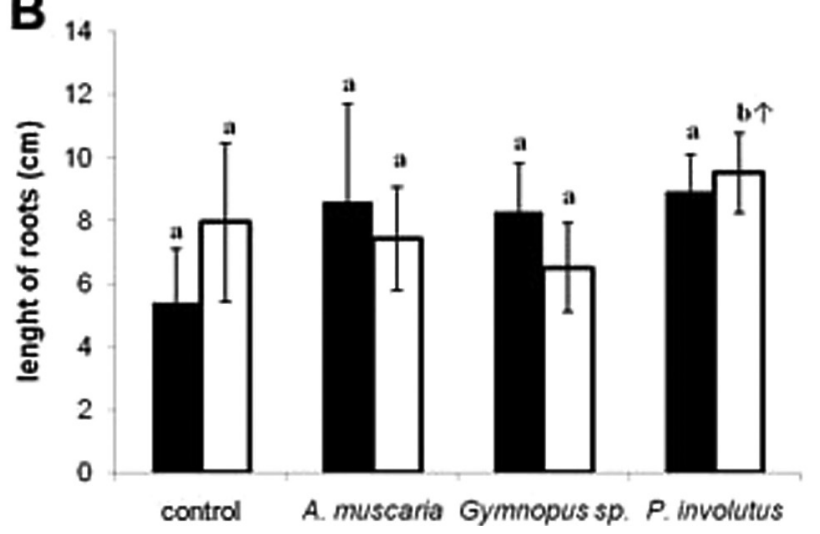

Table 2. Summary two-way ANOVA table testing salinity (S; - or $+\mathrm{NaCl}$ ) and inoculation (I; control, A. muscaria OW-10, Gymnopus sp. OW-6, P. involutus OW-5), and salinity $\times$ inoculation interaction $(\mathrm{S} \times \mathrm{I})$ for each growth parameter and level of proline separately

\begin{tabular}{|c|c|c|c|c|c|c|c|c|c|c|}
\hline \multirow{2}{*}{ Parameter } & \multirow{2}{*}{$\begin{array}{l}\text { Source of } \\
\text { variation }\end{array}$} & \multicolumn{3}{|c|}{ Leaves } & \multicolumn{3}{|c|}{ Stems } & \multicolumn{3}{|c|}{ Roots } \\
\hline & & $\mathrm{MS}^{\mathrm{a}}$ & $\mathrm{F}^{\mathrm{b}}$ & $\mathrm{p}^{\mathrm{c}}$ & MS & $\mathrm{F}$ & $\mathrm{p}$ & MS & $\mathrm{F}$ & $\mathrm{p}$ \\
\hline \multirow[t]{4}{*}{ lenght } & $S$ & - & - & - & 0.0160 & 0.03 & 0.8551 & 0.0300 & 0.08 & 0.9295 \\
\hline & I & - & - & - & 26.0980 & 54.99 & $0.0000 * \mathrm{~d}$ & 16.2140 & 4.32 & $0.0091^{*}$ \\
\hline & $\mathrm{S} \times \mathrm{I}$ & - & - & - & 2.5400 & 5.35 & $0.0030^{*}$ & 11.0200 & 2.93 & $0.0430^{*}$ \\
\hline & Error & - & - & - & 0.4750 & - & - & 3.7550 & - & - \\
\hline \multirow[t]{5}{*}{ fresh mass } & & MS & $\mathrm{F}$ & $\mathrm{p}$ & MS & F & $\mathrm{p}$ & MS & F & $\mathrm{p}$ \\
\hline & S & 0.0003 & 0.11 & 0.7446 & 0.0009 & 1.18 & 0.2942 & 0.0392 & 7.36 & $0.0153^{*}$ \\
\hline & I & 0.1616 & 52.62 & $0.0000 *$ & 0.0227 & 30.46 & $0.0000^{*}$ & 0.0537 & 10.08 & $0.0006^{*}$ \\
\hline & $S \times I$ & 0.0533 & 17.35 & $0.0000^{*}$ & 0.0037 & 4.97 & $0.0127^{*}$ & 0.0505 & 9.49 & $0.0008^{*}$ \\
\hline & Error & 0.0031 & - & - & 0.0007 & - & - & 0.0053 & - & - \\
\hline \multirow[t]{5}{*}{ dry mass } & & MS & $\mathrm{F}$ & $\mathrm{p}$ & MS & $\mathrm{F}$ & $\mathrm{p}$ & MS & F & $\mathrm{p}$ \\
\hline & $S$ & 0.0003 & 0.82 & 0.3785 & 0.0000 & 0.23 & 0.6369 & 0.0000 & 0.05 & 0.8281 \\
\hline & I & 0.0094 & 24.44 & $0.0000^{*}$ & 0.0023 & 15.13 & $0.0001^{*}$ & 0.0014 & 9.52 & $0.0008^{*}$ \\
\hline & $S \times I$ & 0.0021 & 5.51 & $0.0086^{*}$ & 0.0004 & 2.31 & 0.1149 & 0.0009 & 6.24 & $0.0052^{*}$ \\
\hline & Error & 0.0004 & - & - & 0.0002 & - & - & 0.0002 & - & - \\
\hline \multirow{5}{*}{$\begin{array}{l}\text { level } \\
\text { of proline }\end{array}$} & & MS & $\mathrm{F}$ & $\mathrm{p}$ & MS & $\mathrm{F}$ & $\mathrm{p}$ & MS & F & $\mathrm{p}$ \\
\hline & S & 771.37 & 94.32 & $0.0000^{*}$ & 122430.80 & 438.02 & $0.0000 *$ & 92287.10 & 521.48 & $0.0000^{*}$ \\
\hline & I & 1275.61 & 155.98 & $0.0000^{*}$ & 37581.70 & 134.46 & $0.0000^{*}$ & 11088.30 & 62.66 & $0.0000^{*}$ \\
\hline & $S \times I$ & 687.74 & 84.10 & $0.0000^{*}$ & 8570.90 & 30.66 & $0.0000^{*}$ & 24919.70 & 140.81 & $0.0000^{*}$ \\
\hline & Error & 8.18 & - & - & 279.50 & - & - & 177.00 & - & - \\
\hline
\end{tabular}

${ }^{a} \mathrm{MS}$ - mean square; ${ }^{\mathrm{b}} \mathrm{F}$ - ratio of MS to MS error; ${ }^{\mathrm{c}} \mathrm{p}$ - $\mathrm{p}$-value, level of significance; ${ }^{\mathrm{d}}$ significant difference at $\mathrm{p} \leq 0.05$ marked by star symbol $(*)$. 
Effect of salinity and fungal inoculation on the growth parameters and proline level in black alder seedlings

Brown ectomycorrhizae were observed on roots of alder seedlings inoculated with $P$. involutus OW-5. Although ectomycorrhizal root tips were not visible in variant inoculated with $A$. muscaria OW-10, the roots were devoid of root hair. Inoculation with Gymnopus sp. OW-6 caused increased root branching.

Generally, both ectomycorrhizal strains significantly increased growth parameters of alder seedlings in variants without salinity, while saprophytic fungus did not cause such an effect. P. involutus OW-5 significantly enhanced growth also in seedlings treated with $50 \mathrm{mM} \mathrm{NaCl}$, when A. muscaria OW-10 and Gymnopus sp. OW-6 impaired plant growth under these conditions (Fig. 4 and 5). While control plants grew better in substrate with salt than without, in general salinity had no effect on plants inoculated with Gymnopus sp. OW-6 and P. involutus OW-5, except for fresh mass of leaves in seedlings inoculated with $P$. involutus OW-5. The negative effect of salinity was observed for plants inoculated with $A$. muscaria OW-10 (Fig. 5).

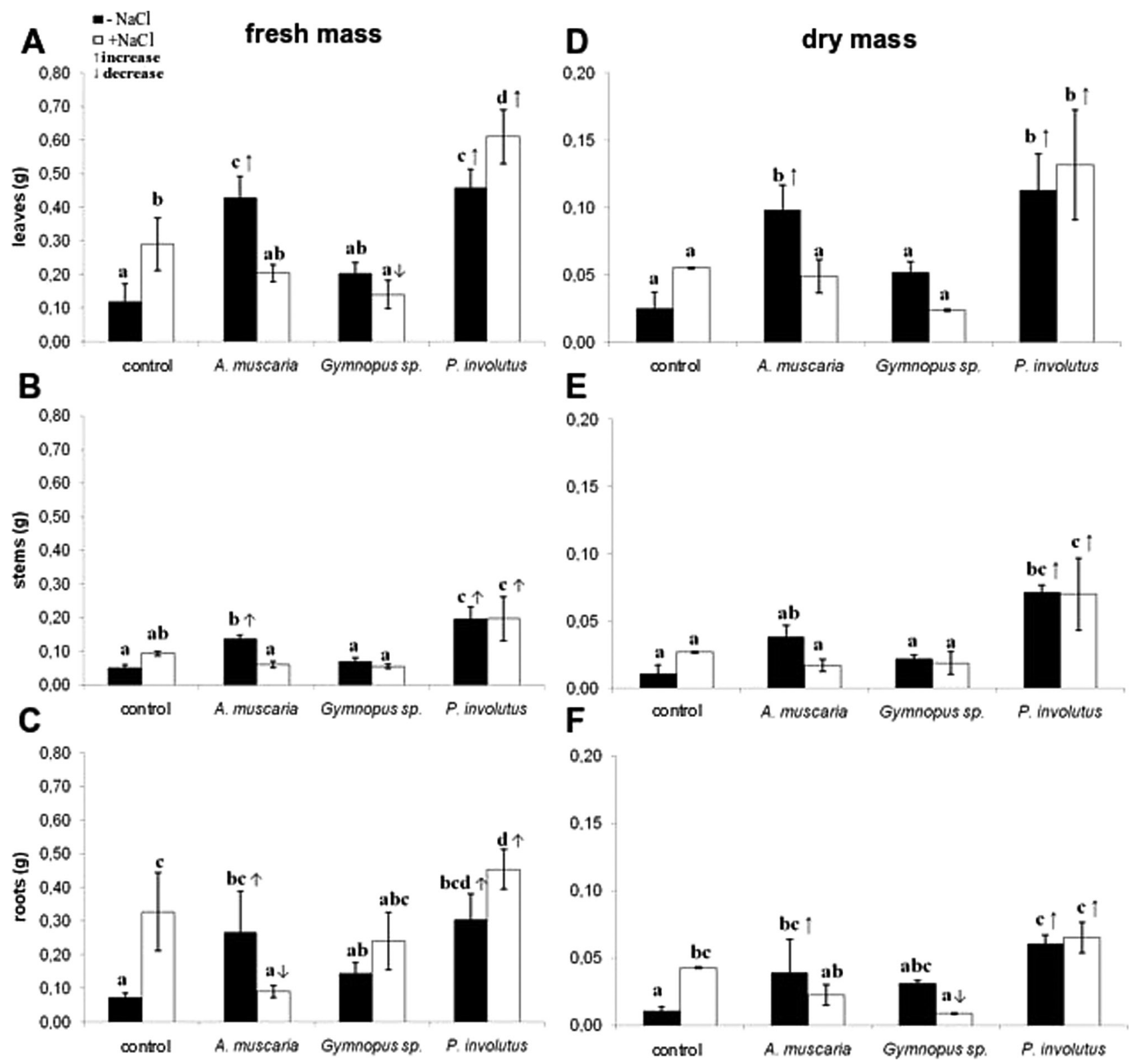

Fig. 5. Fresh and dry mass of seedlings organs (A, D - leaves; B, E - stems; C, F - roots) non-inoculated (control) and inoculated with fungi (Amanita muscaria OW-10, Gymnopus sp. OW-6 or Paxillus involutus OW-5) growing in two variants of substrate without $(-\mathrm{NaCl})$ and with salt $(+\mathrm{NaCl})$ presented as means with standard deviation. Mean values with the same letter are not significantly different ( $\mathrm{p} \leq 0.05$, two-way ANOVA and Newman-Keuls's test). Arrows show significant increase $(\uparrow)$ or decrease $(\downarrow)$ compare to control within the same substrate variant 
In general, the highest levels of proline were observed for stems and the lowest for leaves [stems $(20-180 \mu \mathrm{g} / \mathrm{g}$ f.m. $)>\operatorname{roots}(15-70 \mu \mathrm{g} / \mathrm{g}$ f.m. $)>$ leaves $(0-35 \mu \mathrm{g} / \mathrm{g}$ f.m.)] (Fig. 6). Inoculated variants had significantly higher concentration of proline in the absence of salt in all organs, and in leaves when they grew in substrate containing $\mathrm{NaCl}$. In the presence of salinity only inoculation with $A$. muscaria OW-10 caused a significant increase of proline in stems while the opposite tendency was observed for Gymnopus sp. OW-6 in roots $(+\mathrm{NaCl})$ (Fig. 6). The presence of salinity significantly decreased the levels of proline in stems and roots in control and

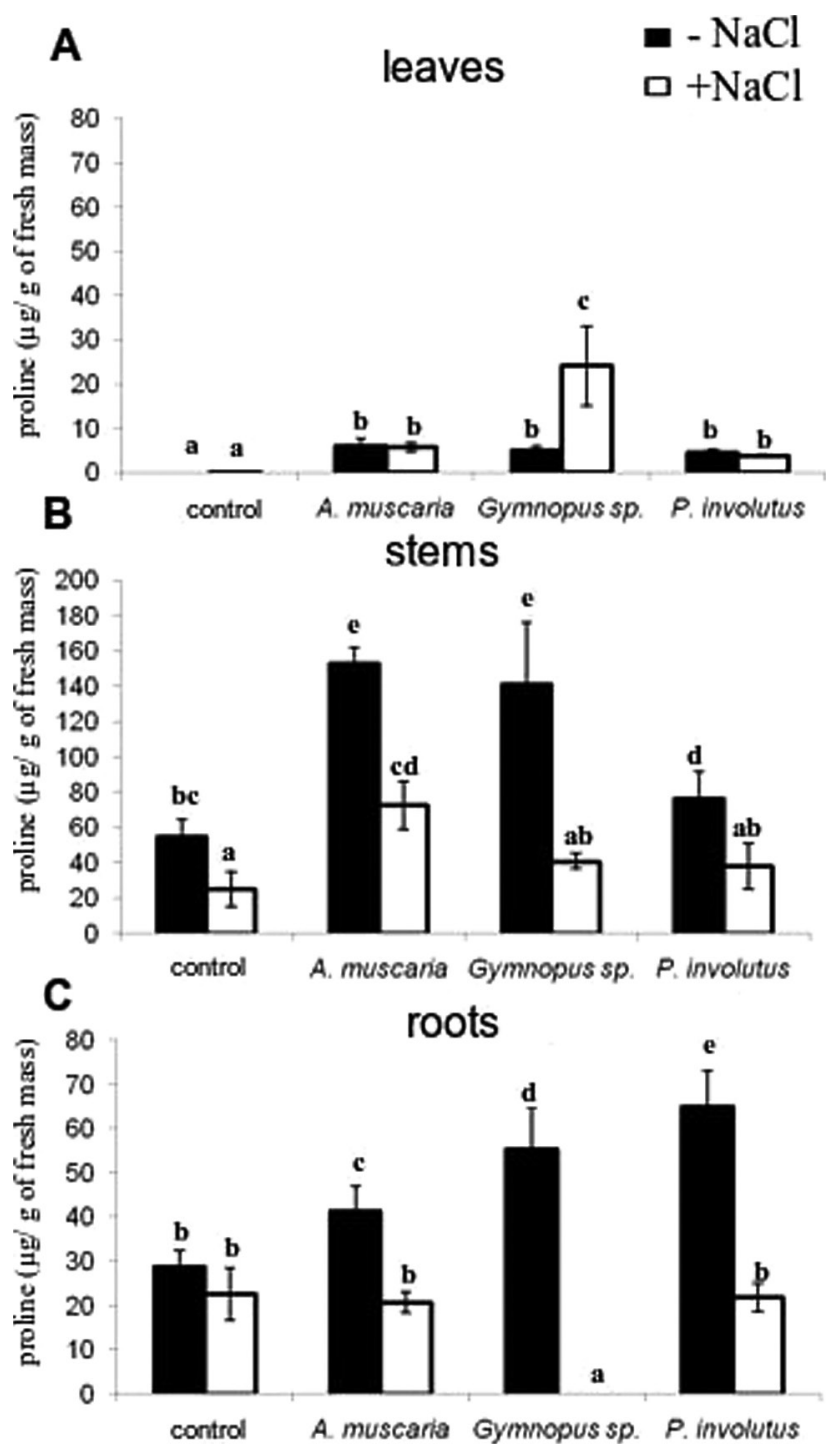

Fig. 6. The level of proline $(\mu \mathrm{g} / \mathrm{g}$ of fresh mass) in (A) leaves, (B) stems, and (C) roots of seedlings non-inoculated (control) and inoculated with fungi (Amanita muscaria OW-10, Gymnopus sp. OW-6 or Paxillus involutus OW-5) in two variants of substrate without $(-\mathrm{NaCl})$ and with salt $(+\mathrm{NaCl})$ presented as mean values with standard deviation. Mean values with the same letter are not significantly different ( $\mathrm{p} \leq 0.05$, two-way ANOVA and Newman-Keuls's test) all inoculated variants. Significantly increase of proline levels was observed in leaves of plants inoculated with Gymnopus sp. OW-6 in the presence of salt (Fig. 6).

\section{Discussion}

Fungal inoculation can be an important tool in promoting trees growth and decreasing abiotic stress effects (Chen et al., 2014; Kayama \& Yamanaka, 2014; Yang et al., 2014). Searching for fungal strains with plant growth promoting properties and able to survive under specific unfavorable soil conditions is crucial, especially in light of growing area of lands affected by different environmental pollution. In general, fungi are more sensitive to unfavorable environmental conditions compared to bacteria, and this is why diversity and number of fungal strains can be lower at sites affected by adverse factors. In our studies, a low number of fruitbodies present at all investigated sites can be related to salinity, which can inhibit their formation by reducing the availability of water and nutrients. Low number of sporocarps under unfavorable environmental conditions was also observed by others, e.g. at three former silver mining sites (Hrynkiewicz et al., 2008) or on area affected by nitrogen and phosphorus fertilization (Baum et al., 2000). The saprophytic strain (Gymnopus sp. OW-6) investigated in our work, revealed higher potential to synthesize hydrolytic enzymes, compared to mycorrhizal ones (A. muscaria OW-10 and P. involutus OW-5). This can be due to the fact that Gymnopus sp. OW-6, being a free-living microorganism, needs a broader range of enzymatic activities than mycorrhizal fungi that exchange nutrients with the host plant. The same tendency was observed by Lyr (1963) who studied pectinolytic and celulolytic activity of different mycorrhizal, pathogenic and saprophytic fungi. Author showed that cellulolytic and pectolytic activities of saprophytic fungi were significantly higher compared to mycorrhizal ones.

Siderophores were synthetized by all fungal isolates investigated in this work. However, $P$. involutus OW-5 showed the highest synthesis of secondary metabolites (siderophores and polyamines). Synthesis of siderophores by plant-associated microorganisms is an effective mechanism protecting host-plants against different abiotic stresses such as salinity (Li et al., 2017; Złoch et al., 2016) or heavy metal contamination (Hrynkiewicz \& Baum, 2006). Positive effect of microorganism-synthesized siderophores on plants growing under saline conditions was already confirmed (Furtado et al., 2019). However, mechanisms involved in this process still remain unknown. 
Polyamines are low-weight organic molecules that play a pivotal role in plant stress tolerance under unfavorable environmental conditions (Todorova et al., 2013). The ability of EM fungus P. involutus to synthesize and release free forms of polyamines, both in the presence of abiotic stress (e.g.; heavy metal contamination) or under control conditions, was demonstrated by many researches (e.g.; Zarb \& Walters, 1996; Fornalé et al., 1999). However, the positive effect of seedling inoculation with polyamine-synthesizing $P$. involutus, under salinity stress, was confirmed in our work for the first time.

Salinity tolerance of fungal strains analyzed in our work decreased in the following order: $A$. muscaria OW-10 > P. involutus OW-5 > Gymnopus sp. OW6. All fungal strains revealed the best growth at the salinity $50-100 \mathrm{mM} \mathrm{NaCl}$, which allowed to classify them to the group of halotolerant microorganisms (Evans et al., 2013). Kernaghan et al. (2002) showed that growth of some fungi coming from Boletales, including $P$. involutus, can be inhibited by high levels of $\mathrm{NaCl}$, which is in line with our study. Based on results of this experiment, we decided to use the $50 \mathrm{mM} \mathrm{NaCl}$ salinity concentration in the pot experiment.

The optimal growth of black alder seedlings was observed in the substrate with $\mathrm{NaCl}$. Moreover, proline level, which is known as a stress indicator, is lower in plant organs exposed to salinity. The above relation was observed both in the control and inoculated variants. The highest concentration of proline in stems may be related with rapid cell growth and stem elongation because proline is utilized by plant in different development processes such as the regulation of cell division, cell wall building and cell extension that occur during stem elongation (Matiolli et al., 2009; Kavi Kishor et al., 2015).

Both ectomycorrhizal strains (A. muscaria OW10 and P. involutus OW-5) used in our experiments were effective in improving plants growth in control conditions, while P. involutus OW-5 also in saline substrate. The stimulatory effect on tree seedlings growth after inoculation by different $P$. involutus strains was observed also by Niemi et al. (2002). In this experiment, inoculation caused rooting stimulation and subsequent growth of Scots pine hypocotyl cuttings in vitro. The inoculation of Populus sp. seedlings with lead tolerant $P$. involutus increased shoot length and dry mass of roots, shoots and leaves (Szuba et al., 2017). Our results are also in agreement with the study of Langenfeld-Heyser et al. (2007), who found that mycorrhization with salt tolerant $P$. involutus resulted in higher whole-plant biomass production under non-stressed conditions. Some authors emphasized positive impact of $P$. involutus strains on tree growth under exposure to different abiotic stresses such as salinity (Langenfeld-Heyser et al., 2007), drought (Luo et al., 2009), tailings compounds (Beaudoin-Nadeau et al., 2016) or heavy metal contamination (Li et al., 2012; Szuba et al., 2017), but reports onblack alder are missing. To the best of our knowledge, only few reports indicated the positive effect of $A$. muscaria on tree growth, and they generally concerned improvement of phytoextraction processes in heavy metal contaminated areas. Brown \& Wilkins (1985) showed a higher dry mass of A. muscaria-inoculated Betula sp. plants compared to non-inoculated trees under exposure to zinc contamination. On the contrary, the negative effect of A. muscaria inoculation was observed in studies conducted by Hrynkiewicz \& Baum (2012) who demonstrated inhibition effect on the biomass production of Salix dasyclados and S. viminalis.

Dighton et al. (1987) confirmed the positive effect of a saprotrophic fungus on plant growth mediated by increasing of nutrients availability in soils. In our study, the application of saprothropic Gymnopus sp. OW-6 had no effect on growth parameters of alder seedlings neither in control nor in saline substrate. It may be related with our earlier observation that Gymnopus sp. OW-6 synthetize a broad range of hydrolytic enzymes, which enables using nutrients from the growth substrate to build its own hyphae.

Generally, increased concentration of amino acids in the inoculated plant's tissues can be related with important role of proline in protection against metabolically damaging processes. The interaction with fungi used for inoculation can be one of such energy consuming processes. As mentioned earlier, especially the saprophytic fungi, but also the mycorrhizal ones secrete hydrolytic enzymes (pectinolytic and celulolytic) which potentially can damage plant cell wall. Proline and hydroxyproline are major constituents of cell wall glycoproteins such as extensins, arabinogalactanoproteins and Hyp/proline (Pro)-Rich proteins (Kavi Kishor et al., 2015). These extracellular proteins are synthesized in response to different external stimuli (Kavi Kishor et al., 2015) and may be involved in cell wall remodeling under a challenge imposed by the hydrolytic activity of fungi-produced enzymes. This may explain the increase of proline levels in roots and stems of fungi-inoculated plants. Noteworthy, the effect occurred both in roots and stems - organs which establish a relatively closer contact with a fungi, but it was absent in leaves. Increased levels of proline in leaves of plants inoculated with mycorrhizal fungus compared to non-inoculated ones was observed also in study of Ruiz-Lozano et al. (1995). Similarly to our study they showed higher proline accumulation in leaves of inoculated plants under drought conditions. We also observed differences in proline accumulation among the fungal symbioses. Fungi were able to induce different degrees of osmotic adjustment depending on 
plant organ and species. Although $P$. involutus OW-5 revealed lower tolerance to salinity compared to $A$. muscaria OW-10 in the in vitro studies, its positive impact on the growth of A. glutinosa seedlings was confirmed in the pot experiment, both in control and saline conditions. This effect may be related with high metabolic activity of this strain, e.g. synthesis of siderophores or polyamines. Stimulation of plant biomass after inoculation with $P$. involutus OW-5 can be related with the higher levels of proline.

Since our study was performed in vitro and in pots, immense effect of soil conditions and other environmental parameters on symbiosis development should be analyzed in future experiments. For this reason, we plan to continue our studies with the use of halotolerant fungal strains selected in this work as potential plant inoculum in natural forests ecosystem.

\section{Acknowledgments}

This study was financially supported by the National Science Centre (Poland) PRELUDIUM 2016/23/N/NZ8/00294.

\section{References}

Ábrahám E, Hourton-Cabassa C, Erdei L \& Szabados L (2010) Methods for determination of proline in plants: Plant tress tolerance (ed. by R Sunkar) Humana Press, Totowa, New Jersey, pp. 317-331.

Aguilar-Aguilar S, Perez J, Ferrera-Cerrato R, Grimaldo O, Cervantes-Díaz L \& González-Mendoza D (2009) Hongos ectomicorrícicos y la tolerancia a la salinidad en plantas. Revista chilena de historia natural 82: 163-168. doi:10.4067/S0716078X2009000100011.

Alexander DB \& Zuberer DA (1991) Use of chrome azurol $S$ reagents to evaluate siderophore production by rhizosphere bacteria. Biology and Fertility of Soils 12: 39-45.

Amprayan K, Rose MT, Kecskes M, Pereg L, Nguyen HT \& Kennedy IR (2012) Plant growth promoting characteristics of soil yeast (Candida tropicalis HY) and its effectiveness for promoting rice growth. Applied Soil Ecology 61: 295-299.

Bandou E, Lebailly F, Muller F, Dulormne M, Toribio A, Chabrol J, Courtecuisse R, Plenchette C, Prin Y, Duponnois R, Thiao M, Sylla S, Dreyfus B \& Bâ AM (2006) The ectomycorrhizal fungus Scleroderma bermudense alleviates salt stress in seagrape (Coccoloba uvifera L.) seedlings. Mycorrhiza 16: 559-565. doi:10.1007/s00572-006-0073-6.

Baum C \& Makeschin F (2000) Effects of nitrogen and phosphorus fertilization on mycorrhizal formation of two poplar clones (Populus trichocarpa and P. trem- ula $\times$ tremuloides). Aspen Bibliography 163: 491497. doi:10.1002/1522-2624(200010)163:53.0. CO;2-3.

Beaudoin-Nadeau M, Gagné A, Bissonnette C, Bélanger P, Fortin JA, Roy S, Greer CW \& Khasa DP (2016) Performance of ectomycorrhizal alders exposed to specific Canadian oil sands tailing stressors under in vivo bipartite symbiotic conditions. Canadian Journal of Microbiology 62: 543-549.

Beltrano J, Ruscitti M, Arango M \& Ronco M (2013) Effects of arbuscular mycorrhiza inoculation on plant growth, biological and physiological parameters and mineral nutrition in pepper grown under different salinity and p levels. Journal of Soil Science and Plant Nutrition 13: 123-141. doi:10.4067/S0718-95162013005000012.

Berg B \& Pettersson G (1977) Location and formation of cellulases in Trichoderma viride. Journal of Applied Bacteriology 42: 65-75.

Brown MT \& Wilkins DA (1985) Zinc tolerance of mycorrhizal Betula spp. New Phytologist 99: 101106.

Burbianka M \& Pliszka A (1977) Mikrobiologia żywności. Wydawnictwo Lekarskie PZWL, Warszawa.

Cantrell SA, Casillas-Martinez L \& Molina M (2006) Characterization of fungi from hypersaline environments of solar salterns using morphological and molecular techniques. Mycological Research 110: 962-970.

Chang P, Gerhardt KE, Huang XD, Yu XM, Glick BR, Gerwing PD \& Greenberg BM (2014) Plant growth-promoting bacteria facilitate the growth of barley and oats in salt-impacted soil: implications for phytoremediation of saline soils. International Journal of Phytoremediation 16: 11331147.

Chen DM, Ellul S, Herdman K \& Cairney JWG (2001) Influence of salinity on biomass production by Australian Pisolithus spp. isolates. Mycorrhiza. 11: 231-236. doi:10.1007/s005720100126.

Chen S, Hawighorst P, Sun J \& Polle A (2014) Salt tolerance in Populus: Significance of stress signaling networks, mycorrhization, and soil amendments for cellular and whole-plant nutrition. Environmental and Experimental Botany 107: 113-124. doi:10.1016/j.envexpbot.2014.06.001.

Dadlez R \& Jaroszewski W (1994) Tectonics. PWN, Warsaw.

Diagne N, Arumugam K, Ngom M, Nambiar-Veetil M, Franche C, Narayanan KK \& Laplaze L (2013) Use of Frankia and actinorhizal plants for degraded lands reclamation. BioMed Research International, e: 948258. doi:10.1155/2013/948258.

Dighton J, Thomas ED \& Latter PM (1987) Interactions between tree roots, mycorrhizas, a sapro- 
trophic fungus and the decomposition of organic substrates in a microcosm. Biology and Fertility of Soils 4: 145-150. doi:10.1007/BF00256988.

Dutta AK, Wilson AW, Antonín V \& Acharya K (2015) Taxonomic and phylogenetic study on gymnopoid fungi from Eastern India. I. Mycological Progress 14: 79. doi:10.1007/s11557-015-1094-3.

Evans S, Hansen RW, Stone HM \& Schneegurt MA (2013) Isolation and characterization of halotolerant soil fungi from the great salt plains of Oklahoma (USA). Cryptogami, Mycolologie 34: 329341. doi:10.7872/crym.v34.iss4.2013.329.

Felsenstein J (1985) Confidence limits on phylogenies: an approach using the bootstrap. Evolution 39: 783-791.

Fornalé S, Sarjala T \& Bagni N (1999) Endogenous polyamine content and metabolism in the ectomycorrhizal fungus Paxillus involutus. New Phytologist 143: 581-587. doi:10.1046/j.14698137.1999.00480.x.

Furtado BU, Szymańska S \& Hrynkiewicz K (2019) A window into fungal endophytism in Salicornia europaea: deciphering fungal characteristics as plant growth promoting agents. Plant and Soil 445: 577-594. doi:10.1007/s11104-019-04315-3.

Gibson T \& Gordon RE (1974) Bacillus: Bergey's Manual of Determinative Bacteriology. 8th Edition. (eds. by RE Buchanan \& NE Gibbons) The Williams and Wilkins Collection, Baltimore, pp. 529-550.

Giri B \& Mukerji K (2004) Mycorrhizal inoculants alleviates salt stress in Sesbania aegyptiaca and Sesbania grandiflora under field conditions: evidence for reduced sodium and improved magnesium uptake. Mycorrhiza 14: 307-312.

Hajiboland R, Aliasgharzadeh N, Laiegh SF \& Poschenrieder C (2010) Colonization with arbuscular mycorrhizal fungi improves salinity tolerance of tomato (Solanum lycopersicum L.) plants. Plant and Soil 331: 313-327. doi:10.1007/s11104-0090255-z.

Högberg MN \& Högberg P (2002) Extramatrical ectomycorrhizal mycelium contributes one-third of microbial biomass and produces, together with associated roots, half the dissolved organic carbon in a forest soil. New Phytologist 154: 791-795. doi:10.1046/j.1469-8137.2002.00417.x.

Hrynkiewicz K, Haug I \& Baum C (2008) Ectomycorrhizal community structure under willows at former ore mining sites. European Journal of Soil Biology 44: 37-44. doi:10.1016/j.ejsobi.2007.10.004.

Hrynkiewicz K \& Baum C (2012) The potential of rhizosphere microorganisms to promote the plant growth in disturbed soils: Environmental protection strategies for sustainable development (ed. by A Malik \& E Grohmann) Strategies for Sustainability. Springer, Dordrecht, pp. 35-64.

Hrynkiewicz K, Baum C, Leinweber P, Weih M \& Dimitriou I (2010) The significance of rotation periods for mycorrhiza formation in short rotation coppice. Forest Ecology Management 260: 1943-1949. doi:10.1016/j.foreco.2010.08.020.

Hrynkiewicz K \& Baum C (2006) Selection of ectomycorrhizal willow genotype in phytoextraction of heavy metals. Environmental Technology 34: 225-230.

Hrynkiewicz K, Szymańska S, Piernik A \& Thiem D (2015) Ectomycorrhizal community structure of Salix and Betula spp. at a saline site in central Poland in relation to the seasons and soil parameters. Water Air and Soil Pollution 226: e99. doi:10.1007/s11270-015-2308-7.

Jang S, Jang Y, Lim YW, Kim C, Ahn BJ, Lee SS \& Kim JJ (2016) Phylogenetic identification of Korean Gymnopus spp. and the first report of 3 species: G. iocephalus, G. polygrammus, and G. subnudus. Mycobiology 44: 131-136. doi:10.5941/ MYCO.2016.44.3.131.

Kayama M \& Yamanaka T (2014) Growth characteristics of ectomycorrhizal seedlings of Quercus glauca, Quercus salicina, and Castanopsis cuspidata planted on acidic soil. Trees 28: 569-583. doi:10.1007/s00468-013-0973-y.

Kernaghan G, Hambling B, Fung M \& Khasa D (2002) In vitro selection of boreal ectomycorrhizal fungi for use in reclamation of saline-alkaline habitats. Restoration Ecology 10: 43-51.

Kavi Kishor PB, Hima Kumari P, Sunita MSL \& Sreenivasulu N (2015) Role of proline in cell wall synthesis and plant development and its implications in plant ontogeny. Frontiers in Plant Science 6: e544. doi:10.3389/fpls.2015.00544.

Kubartová A, Ranger J, Berthelin J \& Beguiristain T (2009) Diversity and decomposing ability of saprophytic fungi from temperate forest litter. Microbial Ecology 58: 98-107. doi:10.1007/s00248008-9458-8.

Kumar S, Stecher G, Li M, Knyaz C \& Tamura K (2018) MEGA X: Molecular evolutionary genetics analysis across computing platforms. Molecular Biology and Evolution 35: 1547-1549.

Langenfeld-Heyser R, Gao J, Ducic T, Tachd P, Lu CF, Fritz E, Gafur A \& Polle A (2007) Paxillus involutus mycorrhiza attenuate $\mathrm{NaCl}$-stress responses in the salt-sensitive hybrid poplar Populus $\mathrm{x}$ canescens. Mycorrhiza 17: 121-131. doi:10.1007/ s00572-006-0084-3.

Li J, Bao S, Zhang Y, Ma X, Mishra-Knyrim M, Sun J, Sa G, Shen X, Polle A \& Chen S (2012) Paxillus involutus strains MAJ and NAU mediate $\mathrm{K}^{+} / \mathrm{Na}^{+}$homeostasis in ectomycorrhizal Populus $\mathrm{x}$ canescens under sodium chloride stress. 
Plant Physiology 159: 1771-1786. doi:10.1104/ pp.112.195370.

Li X, Han S, Wang G, Liu X, Amombo E, Xie Y \& Fu J (2017) The fungus Aspergillus aculeatus enhances salt-stress tolerance, metabolite accumulation, and improves forage quality in perennial ryegrass. Frontiers in Microbiology 8: e1664. doi:10.3389/ fmicb.2017.01664.

Lingappa Y \& Lockwood JL (1962) Chitin media for selective isolation and culture of actinomycetes. Phytopathology 52: 317-323.

Luo ZB, Janz D, Jiang X, Gobel C, Wildhagen H, Tan Y, Rennenberg H, Feussner I \& Polle A (2009) Upgrading root physiology for stress tolerance by ectomycorrhizas: insights from metabolite and transcriptional profiling into reprogramming for stress anticipation. Plant Physiology 151: 19021917. doi:10.1104/pp.109.143735.

Lyr H (1963) Zur frage des streubbaus durch ektotrophe mykorrhiza pilae: Mykorrhiza (ed. by W Rawald \& H Lyr) International Mykorrhiza Symposium. Weimar, Jena, pp. 123-142.

Markovskaja S (2013) Melampsoridium hiratsukanum invasive rust species in Lithuania, and its co-occurrence with eriophylid mite. Acta Mycologica 48: 197-205. doi:10.5586/am.2013.021.

Matiolli R, Costantino P \& Trovato M (2009) Proline accumulation in plants. Plant Signaling \& Behavior 4: 1016-1018. doi:10.4161/psb.4.11.9797.

McLaughlin DJ (1970) Environmental control of fruitbody development in Boletus rubinellus in axenic culture. Mycologia 62: 307-331. doi:10.1080 /00275514.1970.12018970.

Niemi K, Vuorinen T, Ernstsen \& Häggman H A (2002) Ectomycorrhizal fungi and exogenous auxins influence root and mycorrhiza formation of Scots pine hypocotyl cuttings in vitro. Tree Physiology 22: 1231-1239. doi:10.1093/treephys/22.17.1231.

Nilsson RH, Larsson KH, Taylor AFS, Bengtsson-Palme J, Jeppesen TS, Schigel D, Kennedy P, Picard K, Glöckner FO, Tedersoo L, Saar I, Kõljalg U \& Abarenkov K (2018) The UNITE database for molecular identification of fungi: handling dark taxa and parallel taxonomic classifications. Nucleic Acids Research 47: D259-D264. doi:10.1093/ nar/gky1022.

Oliveira SF, Bocayuva MF, Veloso TG, Bazzolli DM, Canedo da Silva CC, Pereira OL \& Kasuya MC (2014) Endophytic and mycorrhizal fungi associated with roots of endangered native orchids from the atlantic forest. Brazil. Mycorrhiza 24: 55-64. doi:10.1007/s00572-013-0512-0.

Pikovskaya RI (1948) Mobilization of phosphorus in soil in connection with the vital activity of some microbial species. Microbiology 17: 362-370.
Ruiz-Lozano JM, Azcón R \& Gomez M (1995) Effects of arbuscular mycorrhizal Glomus species on drought tolerance: physiological and nutritional plant responses. Applied Environmental Microbiology 61: 456-460.

Saitou N \& Nei M (1987) The neighbor-joining method: A new method for reconstructing phylogenetic trees. Molecular Biology and Evolution 4: 406-425.

Séne S, Avril R, Chaintreuil C, Geoffroy A, Ndiaye C, Diédhiou AG, Sadio O, Courtecuisse R, Sylla SN, Selosse M-A \& Bâ A (2015) Ectomycorrhizal fungal communities of Coccoloba uvifera (L.) mature trees and seedlings in the neotropical coastal forests of Guadeloupe (Lesser Antilles). Mycorrhiza 25: 547-559.

Sharma S, Kulkarni J \& Jha B (2016) Halotolerant rhizobacteria promote growth and enhance salinity tolerance in peanut. Frontiers in Microbiology 7: 1600. doi:10.3389/fmicb.2016.01600.

Sharifi M, Ghorbanli M \& Ebrahimzadeh H (2007) Improved growth of salinity-stressed soybean after inoculation with salt pre-treated mycorrhizal fungi. Journal of Plant Physiology 164: 11441151. doi:10.1016/j.jplph.2006.06.016.

Smith SE \& Read D (2008) Mycorrhizas in ecological interactions: Mycorrhizal symbiosis. 3rd ed. (ed. by SE Smith \& D Read) Academic Press, New York.

Solla A, Perez-Sierra A, Corcobado T, Haque MM, Diez JJ \& Jung T (2010) Phytophthora alni on Alnus glutinosa reported for the first time in Spain. Plant Pathology 59: 798. doi:10.1111/j.13653059.2009.02254.x.

StatSoft, Inc. (2007) STATISTICA (data analysis software system), version 8.0. www.statsoft.com.

Szuba A, Karliński L, Krzesłowska M \& Hazubska-Przybył T (2017) Inoculation with a Pb-tolerant strain of Paxillus involutus improves growth and $\mathrm{Pb}$ tolerance of Populus $\times$ canescens under in vitro conditions. Plant and Soil 412: 253-266. doi:10.1007/s11104-016-3062-3.

Szymańska S, Dąbrowska G, Tyburski J, Niedojadło K, Piernik A \& Hrynkiewicz K (2019) Boosting the Brassica napus L. tolerance to salinity by the halotolerant strain Pseudomonas stutzeri ISE12. Environmental and Experimental Botany 163: 5568. doi:10.1016/j.envexpbot.2019.04.007.

Tain CY, Feng G, Li XL \& Zhang FS (2004) Different effects of arbuscular mycorrhizal fungal isolates from saline or non-saline soil on salinity tolerance of plants. Applied Soil Ecology 26: 143-148.

Tamura K, Nei M \& Kumar S (2004) Prospects for inferring very large phylogenies by using the neighbor-joining method. Proceedings of the National Academy of Sciences 101: 11030-11035. 
Thiem D, Gołębiewski M, Hulisz P, Piernik A \& Hrynkiewicz K (2018) How does salinity shape bacterial and fungal microbiomes of Alnus glutinosa roots? Frontiers in Microbiology 9: 651. doi:10.3389/fmicb.2018.00651.

Thompson JD, Gibson TJ, Plewniak F, Jeanmougin F \& Higgins DG (1997) The CLUSTAL-X windows interface: flexible strategies for multiple sequence alignment aided by quality analysis tools. Nucleid Acid Research 25: 4876-4882.

Todorova D, Katerova Z, Sergiev I \& Alexieva V (2013) Role of polyamines in alleviating salt stress: Ecophysiology and responses of plants under salt stress (ed. by P Ahmad, MM Azooz \& MNV Prasad) Springer, New York, pp. 355-379.

Yan N, Marschner P, Cao W, Zuo C \& Qin W (2015) Influence of salinity and water content on soil microorganisms. International Soil and Water Conservation Research 3: 316-323. doi:10.1016/j. iswcr.2015.11.003.
Yang SJ, Zhang ZL, Xue YX, Zhang ZF \& Shi SY (2014) Arbuscular mycorrhizal fungi increase salt tolerance of apple seedlings. Botanical Studies 55: 4-7. doi:10.1186/s40529-014-0070-6.

Zarb J \& Walters DR (1996) Polyamine biosynthesis in the ectomycorrhizal fungus Paxillus involutus exposed to lead. Mycological Research 100: 486-488.

Zarei M \& Paymaneh Z (2014) Effect of salinity and arbuscular mycorrhizal fungi on growth and some physiological parameters of Citrus jambheri. Archives of Agronomy and Soil Science 60: 9931004. doi:10.1080/03650340.2013.853289.

Zou YN \& Wu QS (2011) Efficiencies of five arbuscular mycorrhizal fungi in alleviating salt stress of trifoliate orange. International Journal of Agriculture and Biology 13: 991-995.

Złoch M, Thiem D, Gadzała-Kopciuch R \& Hrynkiewicz K (2016) Synthesis of siderophores by plant-associated metallotolerant bacteria under exposure to $\mathrm{Cd}^{2+}$. Chemosphere 156: 312-325. 